\title{
Situs inversus completus
}

M. A. Walter ${ }^{1}$, P.C. Burger2, M.E. Pfisterer2, J. Müller-Brand ${ }^{1}$, M.J. Zellweger2

${ }^{1}$ Institute of Nuclear Medicine, University Hospital Basel, Basel, Switzerland

2 Department of Cardiology, University Hospital Basel, Switzerland

Published online: 11 July 2003

(c) Springer-Verlag 2003

Eur J Nucl Med Mol Imaging (2003) 30:1202

DOI 10.1007/s00259-003-1239-5

\section{A. Walter (ब)}

Institute of Nuclear Medicine, University Hospital Basel,

Petersgraben 4, 4031 Basel, Switzerland

e-mail: m.a.walter@gmx.net

Tel.: +41-61-2654808

\section{Editor's comment}

Recognition of situs inversus is important for preventing diagnostic and surgical mishaps that result from the failure to recognise reversed anatomy or an atypical history.

Right: Short, vertical long and horizontal long axes (from top to bottom) of the myocardial perfusion study.

Left: Raw data after application of $99 \mathrm{mTc}-\mathrm{MIBI}$.
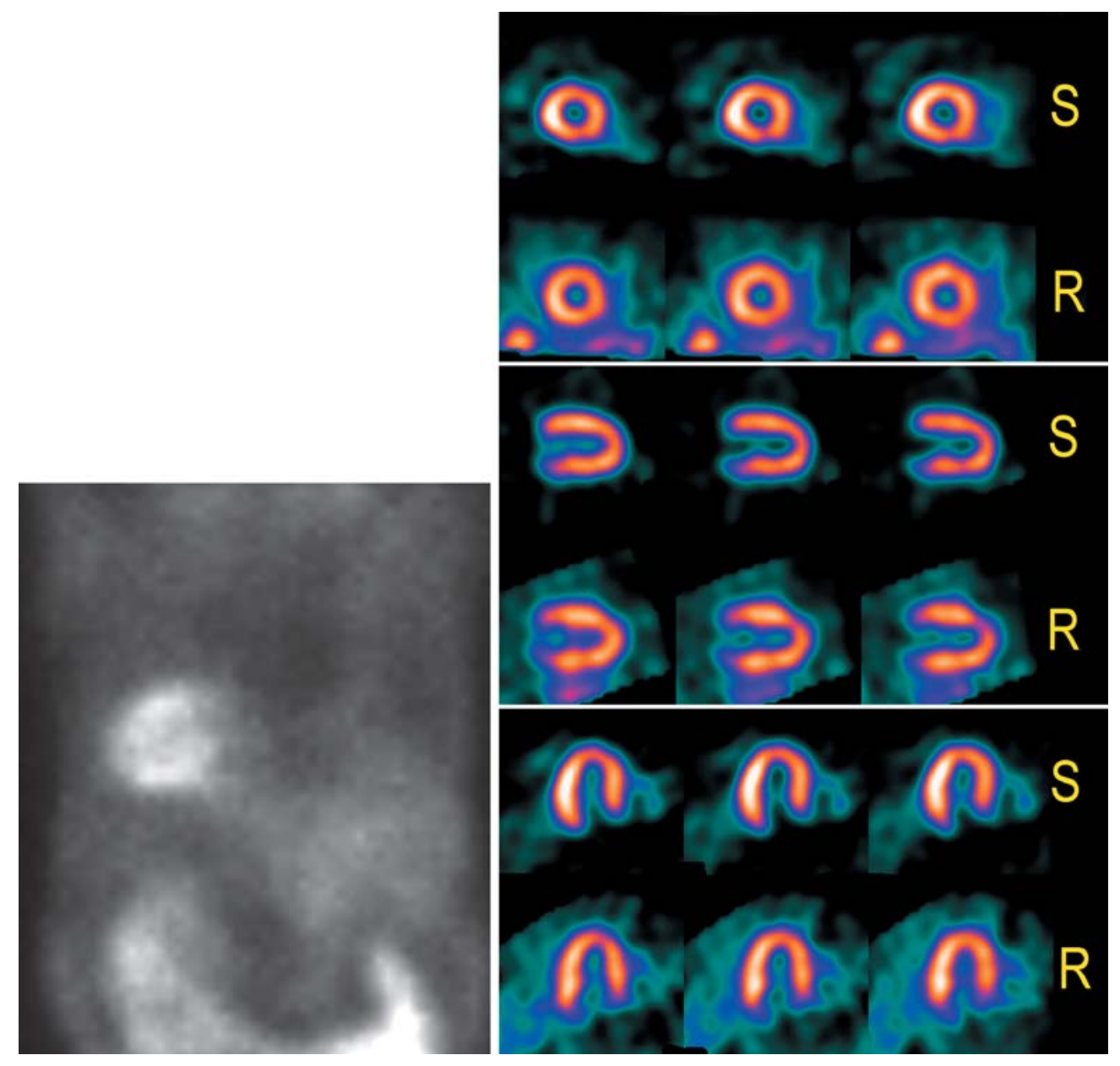